\title{
Gene Expression Pattern of PI3K/AKTPathway Based on Insulin Resistance and Vitamin D Toward the Understanding of T2DM Pathogenesis
}

\section{Somayeh Alsadat Hosseini Khorami}

University of Manitoba Faculty of Agricultural and Food Sciences

Mohd Sokhini Abd Mutalib

Universiti Putra Malaysia

Mohammad Feili Shiraz

Qazvin Islamic Azad University

Joseph Anthony Abdullah

Universiti Putra Malaysia

\section{Zulida Rejali}

Universiti Putra Malaysia

\section{Razana Mohd Ali}

Universiti Putra Malaysia

huzwah Khaza'ai ( $\nabla$ huzwah@upm.edu.my )

Universiti Putra Malaysia

Research article

Keywords: PI3K/AKT pathway, PTEN; GLUT4, vitamin D, gene expression, T2DM, RT-PCR

Posted Date: May 7th, 2020

DOI: https://doi.org/10.21203/rs.3.rs-22403/v1

License: (9) (i) This work is licensed under a Creative Commons Attribution 4.0 International License.

Read Full License 


\section{Abstract}

Background Insulin-stimulated glucose transport occurs via PI3K/AKT-dependent pathway which results in GLUT4 translocation from intracellular vesicles to plasma membrane and glucose uptake. PTEN, as a phosphatase, is the main antagonist of the PI3K/AKT pathway's kinases. Present study was performed to investigate underlying mechanism responsible for defects in insulin signaling and the plausible role of vitamin $D$ in pathogenesis of T2DM through the comparison of serum vitamin $D$ and expression of genes involved in insulin signaling in diabetics and non-diabetics.

Results RT-PCR was employed to investigate mRNA expression level of IRS1/PI3K/PDK1/AKT2/GLUT4/PTEN in diabetic and non-diabetic participants and serum vitamin D was measured by HPLC. Findings provide evidence that IRS1 expression was preserved while PI3K /AKT2/GLUT4 were expressed significantly lower and PDK1 was expressed significantly higher in diabetics compared to non-diabetics. Albeit there was no significant difference in PTEN expression between groups, it was up-regulated by the years of having diabetes. No significant correlation between serum vitamin $D$ and gene expression of GOls was observed in either group.

Conclusion Since PTEN has been identified as a negative regulator of insulin signaling, it has generated great interest in new therapeutic approaches. This study reveals that insulin resistance is not caused through an alteration in PTEN expression as a primary defect but may be caused by decreased PI3K/AKT2/GLUT4 signalling and dysregulation of feedback loops. Particularly, PTEN expression showed a significant relation with duration of diabetes, suggesting that PTEN may not be the cause of the reduced expression of $P I 3 K / A K T$ pathway in diabetics while it can be the effect of that. Therefore, the future investigations should be focused on regulators of pathway instead of PTEN. No significant correlation between serum vitamin $D$ and gene expression of GOls could be due to the non-linearity relationships as insulin signaling is a cascade with amplifying properties.

\section{Background}

Glucose homeostasis is an essential aspect of insulin action, which impaired insulin regulation of glucose transport through PI3K/AKT pathway results in insulin resistance and Type II diabetes [1]. Insulin initiates its function by interacting with insulin receptors (IRS) and phosphorylated/activated IRS can be reversely dephosphorylated/deactivated by PTEN phosphatase and SHIP2 [2], [3]. Phosphorylated IRS1 binds and activates PI3K which causes to phosphorylation of PIP2 to form PIP3 (PTEN and SHIP2 dephosphorylate PIP3 back to PIP2), then PIP3 interact allosterically with PDK1 and leads to $A K T / P K B$ and PKC phosphorylation to activate GLUT4 translocation to the plasma membrane from intracellular vesicular compartment [4], [5]. Hence, PTEN inactivation leads to PIP3 accumulation and consequently, to the hyper activation of $A K T$, which leads to decrease serum glucose level [6]. This suggests that higher level of PTEN may make individuals more susceptible to the development of Type II diabetes by modulating insulin sensitivity [7]. Overexpression of PTEN in T2DM, results in inhibition of $A K T$ signalling pathway and GLUT4 translocation to the cell membrane, hence decreases glucose uptake. In contrast, 
decreasing of PTEN expression, enhances insulin stimulated AKT phosphorylation [8]. Therefore, regulation of insulin function is performed by the balance between phosphorylation and dephosphorylation of the PISK/AKT pathway components.

The insulin signalling pathway includes multiple feedback loops [9], as phosphorylated/activated $A K T$ phosphorylates and negatively regulates PTEN. This phosphorylation impairs the function of PTEN to dephosphorylate IR and IRS1 [10]. This reveals positive feedback loop ( $A K T$ inhibits signal attenuation PTEN hence inhibits dephosphorylation of the receptor and IRS1) that consists of a double negative feedback loop (phosphorylated kinase (AKT) negatively regulates the phosphatase (PTEN) that dephosphorylates it) (Fig. 1).

Based on tremendous results of some recent studies, there is a relationship between vitamin $D$ and insulin sensitivity not only in both in vitro and in vivo studies but also in epidemiological and clinical studies [11]. However, the mechanism underlying the effects of vitamin D on insulin sensitivity has not been clarified yet. Vitamin D may modulate PTEN and/or other components of the PIJK/AKT pathway hence, affects insulin sensitivity and glucose homeostasis [12], [13]. In our previous study, the effects of vitamins $D$ on an insulin-resistant model of neuronal cells was investigated which caused significant increase in IR, PI3K and GLUT4 expression levels, as well as AKT phosphorylation and glucose uptake [14].

The present study was carried out to investigate the molecular mechanisms of the PISK/AKT pathway responsible for insulin resistance in Type II diabetes. In order to verify whether the regulation of key genes of insulin action is altered in Type II diabetes, mRNA expression level of IRS1, PI3K, PDK1, AKT2, GLUT4 and PTEN in non-diabetics and Type II diabetics were investigated. Also, in order to elucidate the plausible role of vitamin $D$ in pathogenesis of T2DM, the relationship between serum vitamin $D$ concentration and expression level of genes involved in insulin signaling were compared in diabetics and non-diabetics.

\section{Results}

\section{Analysis of mRNA Gene Expression by RT-PCR}

RT-PCR method was employed and optimized with two housekeeping genes (GAPDH and $\beta$-ACTIM) to identify the alterations of IRS1, PI3K, PDK1, AKT2, GLUT4 and PTEN expression levels as GOls (gene of interest) in diabetic participants in compared to non-diabetics.

The amplification curves and melting curves of GOls and housekeeping genes indicated the absence of contaminating products in negative control. The specificity of all primers were evaluated by melt curve analysis and a single amplified product has been observed for all genes.

\section{Relative Quantification Of Gois Expression Levels}


Normalised expression levels of GOls in non-diabetic and diabetic participants are shown in Table 1 and Fig. 2.

Table 1

Relative Quantification of GOls Expression Levels between Diabetic and Non-Diabetic Participants

\begin{tabular}{|c|c|c|c|c|c|}
\hline \multirow[t]{2}{*}{ GOls } & $\begin{array}{l}\text { Non-diabetics } \\
(n=50)\end{array}$ & $\begin{array}{l}\text { Diabetics } \\
(n=50)\end{array}$ & df & $\mathrm{t}$ & P-value \\
\hline & Mean \pm SE & Mean \pm SE & & & \\
\hline IRS1 & $0.23 \pm 0.01$ & $0.21 \pm 0.01$ & 98 & -0.819 & 0.415 \\
\hline $\mathrm{PI} 3 \mathrm{~K}$ & $0.32 \pm 0.02$ & $0.46 \pm 0.02$ & 98 & 3.68 & $0.001^{*}$ \\
\hline PDK1 & $0.70 \pm 0.04$ & $0.57 \pm 0.03$ & 98 & -2.00 & $0.014^{\star}$ \\
\hline AKT2 & $0.68 \pm 0.04$ & $0.87 \pm 0.08$ & 98 & 1.92 & $0.050^{*}$ \\
\hline GLUT4 & $0.74 \pm 0.05$ & $0.95 \pm 0.07$ & 98 & 2.24 & $0.028^{*}$ \\
\hline PTEN & $0.44 \pm 0.03$ & $0.42 \pm 0.03$ & 98 & -0.436 & 0.664 \\
\hline \multicolumn{6}{|c|}{$* \mathrm{P}<0.05$} \\
\hline
\end{tabular}

Gene expression levels of IRS1 and PTEN were higher in Type II diabetic in comparison to non-diabetic participants but there was no significant difference between two groups, whilst the expression of PI3K, AKT2 and GLUT4 were significantly lower and PDK1was higher in Type II diabetic participants.

Further analysis of variables was performed to find out the possible mechanisms responsible for insulin resistance in Type II diabetic participants. Since the time is a proposed new classification system for diabetes [17], the association of duration of diabetes and gene expression level of GOls were investigated in diabetic participants.

\section{Target Genes Expression in Relation to the Duration of Diabetes}

One-way ANOVA was used to compare differences between each of the GOls and duration of diabetes (three groups were considered: $<5,5-10,10<$ years) as an independent variable in diabetic participants and these results are shown in Table 2. 
Table 2

Relation of GOls with Duration of Diabetes in Diabetic Group

\begin{tabular}{|c|c|c|c|c|c|c|}
\hline & & Sum of Squares & df & Mean Square & $\mathbf{F}$ & Sig. \\
\hline \multirow[t]{3}{*}{ IRS1 } & Between Groups & 0.067 & 2 & 0.033 & 3.677 & $0.033^{*}$ \\
\hline & Within Groups & 0.443 & 47 & 0.009 & & \\
\hline & Total & 0.510 & 49 & & & \\
\hline \multirow[t]{3}{*}{ PI3K } & Between Groups & 0.040 & 2 & 0.020 & 0.645 & 0.529 \\
\hline & Within Groups & 1.476 & 47 & 0.031 & & \\
\hline & Total & 1.516 & 49 & & & \\
\hline \multirow[t]{3}{*}{ PDK1 } & Between Groups & 0.165 & 2 & 0.082 & 2.828 & 0.069 \\
\hline & Within Groups & 1.407 & 47 & 0.029 & & \\
\hline & Total & 1.572 & 49 & & & \\
\hline \multirow[t]{3}{*}{ AKT2 } & Between Groups & 0.233 & 2 & 0.117 & 0.337 & 0.714 \\
\hline & Within Groups & 16.301 & 47 & 0.346 & & \\
\hline & Total & 16.534 & 49 & & & \\
\hline \multirow[t]{3}{*}{ GLUT4 } & Between Groups & 0.086 & 2 & 0.043 & 0.190 & 0.827 \\
\hline & Within Groups & 10.481 & 47 & 0.223 & & \\
\hline & Total & 10.568 & 49 & & & \\
\hline \multirow[t]{3}{*}{ PTEN } & Between Groups & 0.282 & 2 & 0.141 & 4.025 & $0.024^{\star}$ \\
\hline & Within Groups & 1.649 & 47 & 0.035 & & \\
\hline & Total & 1.930 & 49 & & & \\
\hline \multicolumn{7}{|c|}{$\star P<0.05$} \\
\hline \multicolumn{7}{|c|}{$\begin{array}{l}\text { PTEN and IRS1 expression level revealed a significant relation with duration of diabetes which } \\
\text { indicates that duration of diabetes is the strongest predictor for increasing of PTEN and IRS1 gene } \\
\text { expression. }\end{array}$} \\
\hline
\end{tabular}

This study provides evidence that the gene expression levels of IRS1 and PTEN were preserved under the conditions in which PDK1 expression was higher and PI3K, AKT2, GLUT4 expression were lower in Type II diabetic participants. These impairments are suggested to be the primary reason for insulin resistance and duration of diabetes is proposed to be the strongest predictor for increasing of PTEN and IRS1 expression. 


\section{Assessment and Comparison of Serum Vitamin D Concentration in Relation to GOls Expression Level}

Serum vitamin D3 concentration $(\mathrm{ng} / \mathrm{mL})$ in diabetic participants were compared to non-diabetics. The average of serum vitamin $D$ concentration was higher in non-diabetics $(33.07 \pm 0.97 \mathrm{ng} / \mathrm{ml}$ ) compared to $(30.47 \pm 1.30 \mathrm{ng} / \mathrm{ml})$ diabetics but the difference was statistically insignificant $(\mathrm{T}:-1.603, \mathrm{df}: 98$ and $P$ value: 0.112 ).

Pearson correlation test was performed to show the plausible relationship between expression levels of GOIs and serum vitamin D concentration which no significant correlation was observed in either group of participants (Table 3).

Table 3

Serum vitamin D level in relation to the gene expression level of GOls in diabetic and non-diabetic participants

\begin{tabular}{|lllll|}
\hline & \multicolumn{2}{l}{ Non-diabetic Participants } & \multicolumn{2}{l|}{ Diabetic Participants } \\
\cline { 2 - 5 } & Pearson Correlation ( $\boldsymbol{r})$ & P-value & Pearson & P-value \\
& & & Correlation $(\boldsymbol{r})$ \\
\hline IRS1 & 0.118 & 0.431 & -0.031 & 0.828 \\
\hline PI3K & -0.252 & 0.083 & -0.034 & 0.814 \\
\hline PDK1 & -0.125 & 0.399 & -0.030 & 0.839 \\
\hline AKT2 & 0.158 & 0.283 & -0.214 & 0.136 \\
\hline GLUT4 & -0.049 & 0.743 & -0.266 & 0.065 \\
\hline PTEN & -0.210 & 0.162 & 0.001 & 0.993 \\
\hline **Correlation is significant at the 0.01 level (2-tailed). & \\
\hline * Correlation is significant at the 0.05 level (2-tailed). \\
\hline
\end{tabular}

\section{Discussion}

Although the necessity of the PI3K/AKT pathway in insulin signal transduction is documented [18], it has not attained sufficient in vivo and in vitro evidence to identify the underlying mechanisms of the pathway and contradictory findings have been reported through knockout and RNAi studies [19]-[21].

It is now commonly accepted that metabolic regulation relies on three types of control which involves; 1 ) Allosteric control of a key enzyme activity that triggers a metabolic pathway by binding to the activator, (mostly its substrate). 2) Posttranslational modifications such as phosphorylation, acetylation, glycosylation and proteolytic cleavage, which may affect the protein stability and/or equilibrium between 
active and inactive enzyme. In these kinds of control, subsequent changes in protein-protein interaction may participate in generating the active/non-active enzymatic complex. 3) Transcriptional regulation such as DNA methylation, which affects the gene expression level of key enzymes and is considered as a longer time regulation scale. Most metabolic regulations rely on a collaboration of these various mechanisms. As the insulin signalling starts at the cell membrane and subsequent events occur via phosphorylation cascades, which mainly happen through the PIJK/AKT pathway, it is probable that a part of the insulin function results from posttranslational modifications of numerous transcription factors [1], [22]-[24].

Insulin resistance in Type II diabetes has been characterized by several defects in the insulin signalling cascade [1], [22]-[24]. These events are related to short-term post-translational regulation of specific protein functions and long-term transcriptional regulation of key genes of insulin signaling pathway [25]. This hypothesis is supported by findings of altered expression of genes encoding metabolic enzymes in Type II diabetic patients [26].

In this study, there was no alteration in insulin signalling at the level of IRS1 and PTEN expression in diabetic participants despite the presence of reduced PI3K, AKT2 and GLUT4 expression levels and increased $P D K 1$ expression. These findings were in agreement with previous studies [27], [28] and suggesting that reduced expression levels of these genes may induce insulin resistance [8]. A contradiction in the results obtained from different investigations [1], [22]-[24] indicates several possible mechanisms of transcriptional regulation of the PI3K/AKT pathway. For instance, in the present study, no significant difference in gene expression of IRS1 and PTEN in diabetic participants suggesting that defects in insulin signalling via IRS1 and PTEN are unlikely to be the primary cause. Another possibility is that these genes exert their main role in the PI3K/AKT pathway, which, beyond a very narrow range of their changes, the homeostasis of the pathway will disappear. Thus, the insulin signalling is very sensitive to the alteration of these components. Otherwise, it should be considered that insignificantly higher level of IRS1 in this study, might be due to the collaboration of various mechanisms including signal amplification as a compensatory mechanism and convergence of other signalling pathways. However, the role of negative feedback loops cannot be neglected, as control of insulin signalling can be achieved by autoregulation whereby downstream elements inhibit upstream components [29], [30]. For example, AKT negatively regulates PTEN and prevents dephosphorylation of IRS1 by PTEN [31]. Therefore, it can be concluded that higher gene expression level of IRS1 could be due to the higher amount of PTEN expression as well as lower $A K T 2$ expression as a compensatory mechanism. Alternatively, signals from other pathways can inhibit insulin signalling. The $I R$ and the IRS are targets for such feedback control mechanisms. Phosphorylation of IRS on Serine residues could be a key step in these feedback control processes [32]-[35]. Most of the Serine/Threonine kinases that are stimulated by insulin, are downstream effectors of IRS and serve as negative modulators of its action. The blockage of these kinases by the $P I 3 K$ pathway inhibitors, indicates that these kinases are downstream of PI3K as potential IRS kinases [33]. Also, insulin resistance inducers such as cellular stress, free fatty acids and tumor necrosis factor-a use similar mechanisms which activate some IRS kinases and inhibit their function by phosphorylation of Serine residues [33], [36]. Serine phosphorylation is considered as a short-term inhibitory mechanism, 
while regulation of IRS expression might promote long-term insulin resistance. Also, it should be considered that as PTEN antagonizes PI3K, it may cause the activation of a feedback loop involving IRS1 by upregulating signalling through $P I 3 K$ [37].

Insulin induces $P I 3 K$-mediated activation of $P D K 1$ and produces PIP3 that regulates $A K T$ activity and its plasma membrane translocation. Interaction between $P D K 1$ and $P K C$ may be required for insulin-induced phosphorylation of $A K T$ [38]. Moreover, $P D K 1$ activates $P K C$ which stimulates gluconeogenesis and contributes to insulin resistance through activation of pyruvate carboxylase [39]. Though, this study did not examine the gene expression level of $P K C$, contribution of endogenous glucose production along with impaired $P / 3 K / A K T$ pathway is proposed in insulin resistance as a result of higher gene expression level of $P D K 1$ in diabetics.

It has been revealed that insulin's signal being mediated by protein phosphatases such as PTEN and SHIP. Knockout and RNAi studies can induce diabetes by up-regulating PTEN. These phosphatases which have different biological functions in vivo, can induce insulin resistance through attenuating the PI3K/AKT pathway [40]. Overexpression of PTEN decreases insulin-stimulated PI3K/AKT pathway, GLUT4 translocation and glucose uptake into the cells [41], [42]. Microinjection of anti-PTEN antibody increases insulin-stimulated GLUT4 translocation to the cell membrane and glucose uptake [41]. Therefore, PTEN reduces insulin sensitivity [43], as it is increased by inhibition of PTEN [44]-[46]. Although numerous phosphatases could be considered to be significant players in insulin signal transduction, only PTEN has been considered in this study. Changes in the abundance of PTPases and their collaboration or interaction may be involved in the pathogenesis of insulin resistance. Therefore, further ex vivo studies are required to assess the underlying mechanisms of PTEN function as well as other phosphatases and differentiate their roles, interaction and collaboration in antagonizing PIJK/AKT pathway and induction of diabetes. Understanding of mechanisms underlying the regulation of PTEN is important to identify its roles in diabetes. Regulation of PTEN is controlled at three steps; transcriptional regulation, post-translational mechanisms and membrane recruitment [18], [47], [48]. Initially it was assumed that PTEN expression is constitutively until numerous transcription factors have been observed that binding directly to PTEN promoter and regulating its expression [47], [49], [50]. Localization of PTEN plays an important role in the regulation of its activity in order to dephosphorylate PIP3 back to PIP2 at the cell membrane [48], [51], [52]. Since, PTEN acts as the main antagonist of the PI3K/AKT signalling pathway by converting PIP3 into PIP2 [53], directly reversing the effects of $P I 3 K$ and deactivating/dephosphorylating $A K T$ through a decrease in PIP3 levels [54], [55]. Reduced concentration of cellular PIP3 has been reported in Type II diabetic participants [56]. Hence, PTEN inactivation leads to PIP3 accumulation and consequently to hyper-activation of $A K T$, which leads to decreased serum glucose level [6]. Therefore, the intracellular concentration of PIP3 and PIP2 is regulated by the PISK/PTEN equilibrium and dysregulation of PI3K/AKT pathway or no equilibrium between the $P I 3 K$ and PTEN concentration might be implicated in Type II diabetes [57].

The findings of the present study showed reduced expression level of PI3K, AKT2 and GLUT4 in diabetic participants compared to non-diabetics, confirming previous studies [27], [28]. Nevertheless, there was no 
significant difference in gene expression level of PTEN and IRS1 in diabetic participants that it was in consistent with the findings of some studies [58]-[60]. This may lead one to the hypothesis that localization of PTEN plays an important role in the regulation of its activity [61]-[64]. It means that the main role of PTEN in regulation of insulin function is performed by dephosphorylating the active form (insulin-stimulated) of insulin receptor and by modulating post-receptor signalling through antagonizing PI3K/AKT pathway [19]-[21]. These findings indicates that PTENs transmembrane function is probably more imperative than its intracellular function in insulin signal attenuation.

From another aspect it can be concluded that, although the PTEN level was higher in diabetic participants than in non-diabetics, the difference was not enough to be statistically significant while it was enough to affect GLUT4 expression. It means that insulin sensitivity is impaired by reduced expression of components that amplify the insulin signalling such as PI3K and $A K T$ [65]-[71]. Even though presence of bistable response has not been proved in insulin signalling pathway and we are waiting for more verifications of this property, there are indications that this pathway includes the required components to exhibit bistable behaviour [65]-[71]. Bistability can be generated due to the non-linearity in positive feedback loops or double negative feedback loops [72]. The non-linearity is due to the ultrasensitive response that is usually obtained through enzymatic cascades [73]. Bistable systems display hysteresis, which means that the signalling system switches between two separate steady states without resting in a transitional state and the required amount of stimulatory input for transition from one state to another is completely different from that required for the reverse transition [74]. The insulin signalling pathway includes multiple feedback loops [9], such as phosphorylated/activated AKT phosphorylates and negatively regulates PTEN. This phosphorylation impairs the function of PTEN to dephosphorylate $I R$ and IRS1 [10] and reveals a positive feedback loop. In other words, AKT inhibits PTEN as a signal attenuation, hence, it inhibits dephosphorylating of IR and IRS. This phenomenon consists of a double negative feedback loop (phosphorylated $A K T$ negatively regulates PTEN that in turn dephosphorylates $A K T$ ). In except of this positive feedback loops considered in PI3K/AKT pathway, it is also known that many feedback loops have not been entirely characterized [9]. Thus, this pathway has the potential to convert stimulatory inputs into bistable responses. Therefore, we cannot rule out the hypothesis that bistablity might exist in insulin-induced glucose absorption due to the ultrasensitivity of GLUT4 expression level in response to the PTEN expression at this study. Our findings indicate that the PIJK/AKT pathway losses bistability beyond a very narrow range of PTEN expression levels in addition to impaired insulin sensitivity by reduced expression of components that amplify the insulin signalling such as PI3K and $A K T$. These results are in accord with the literature on the existence of bistability in insulin signal transduction [65]-[71]. Consequently, PTEN/PI3K could be a phosphatase-kinase couple that controls the transition of the signalling molecule between two phosphorylation states.

Since, the regulation of insulin function is performed by the balance between phosphorylation and dephosphorylation of the PIBK/AKT pathway components and PTEN has been identified as a negative regulator of this pathway, it has generated great interest in new therapeutic approaches. Nevertheless, this study reveals that insulin resistance is caused through reduced PI3K/AKT2/GLUT4 signalling and not through alteration in PTEN expression. Furthermore, significant positive correlation between PTEN 
expression level and duration of diabetes indicates that PTEN expression increases by the years of having diabetes. As the time is a proposed new classification system for diabetes [17], PTEN may not be the cause of the reduced expression of $P / 3 K / A K T$ pathway in diabetics while it can be the effect of that.

According to the several studies [75], vitamin D is required for normal insulin function. A number of studies [76], [77] revealed that vitamin D level is positively correlated with insulin sensitivity and lower risk of impaired glucose tolerance and T2DM. The modulatory action of vitamin $D$ in insulin receptor gene expression and insulin secretion may point to its role in the pathogenesis and development of T2DM [78]. Vitamin $D$ deficiency causes reduced insulin secretion in rats and humans, whereas its replenishment increases glucose tolerance through improvements in $\beta$-cell function [79]. In addition, certain allelic variations in the vitamin D-binding protein (DBP) and vitamin D receptor (VDR) might affect glucose tolerance and insulin secretion [78], [80] thus contributing to the occurrence of T2DM. Furthermore, vitamin $\mathrm{D}$ has been reported to contribute to normalization of extracellular calcium which determines the normal intracellular calcium pool. Increased intracellular calcium impairs phosphorylation of insulin receptors, leading to decreased GLUT4 activity and impaired insulin signal transduction [81], [82]. Also, it has been documented that vitamin D deficiency and obesity in adult C57BL/ 6 mice entailed hyperinsulinemia and impaired expression level of the PI3K/AKT pathway components which caused impaired glucose homeostasis and insulin resistance [12]. Furthermore, it has been demonstrated that vitamin D-induced activation of PISK/AKT pathway is through PTEN down regulation and $A K T$ up regulation [13]. Insulin controls glucose and lipid metabolism through the PISK/AKT pathway and PTEN is a negative regulator of this pathway, hence, down-regulation of PTEN enhances the metabolic effects of insulin [83], [84] and reverses insulin resistance [85], [86].

Nevertheless, it remains to be elucidated whether alterations in insulin signalling gene expression in T2DM are influenced by the regulatory transcriptional properties of vitamin D. Since the active form of vitamin $D, 1,25$-dehydroxyvitamin $D_{3}$, influences expression of various genes [87], [88], the relationship between serum vitamin $\mathrm{D}$ concentration and gene expression level of insulin signal transduction components were assessed.

In this study, there was no significant correlation between serum vitamin D concentration and gene expression level of GOls in either group of participants. Data presented in current report is not in agreement with previous study on vitamin D-induced activation of PI3K/AKT pathway by down regulation of PTEN in mice [13]. Also, in our previous in vitro study, vitamins $D$ increased the expression level of $I R$, PISK and GLUT4 and phosphorylation level of AKT which caused increased glucose uptake on insulinresistant model of neuronal cells [14]. The reason of contradiction between present study and our previous in vitro study [14] could be due to the non-linearity relationships, as the Pearson correlation test shows a linear correlation while insulin signal transduction is a cascade with amplifying properties [65][71]. Also, it should be considered that Pearson correlation test does not reveal the cause and effect relationships. Furthermore, in this study, only five diabetic participants were vitamin D deficient, thus, it was impossible to compare gene expression level of GOls based on vitamin D status. 


\section{Conclusion}

The focus of current study was to ascertain the plausible mechanisms responsible for transcriptional regulation of insulin signalling in humans through the comparison of alterations in expression level of $P I 3 K / A K T$ pathway genes in diabetic individuals. Also, the authors intended to determine the plausible transcriptional regulation of glucose metabolism through vitamin D.

Most reported studies of insulin resistance are based on cell lines and animal models which suggesting increased PTEN expression as a main cause of insulin resistance [89]-[93]. Since, the regulation of insulin function is performed by the balance between phosphorylation and dephosphorylation of the PI3K/AKT pathway components and PTEN has been identified as a negative regulator of this pathway, it has generated great interest in new therapeutic approaches. Nevertheless, this ex vivo study provides novel findings and insights to the insulin signalling pathways in humans and reveals that insulin resistance is caused through reduced PI3K/AKT2/GLUT4 signalling and not through alteration in PTEN expression. Furthermore, significant positive correlation between PTEN expression level and duration of diabetes indicates that PTEN expression increases by the years of having diabetes. It seem that PTEN is not the cause of the reduced expression of PI3K/AKT pathway in diabetics while it is the effect of that. Therefore, the future investigations should be focused on regulators of insulin pathway instead of $P T E N$.

Vitamin D is involved in insulin resistance through genomic and non-genomic molecular actions related to insulin signaling as well as reduction of oxidative stress, inflammation and regulation of gene expression. In this study, no significant correlations between serum vitamin D concentration and gene expression level of GOls were observed in either group of participants. This result could be due to the nonlinearity relationship as the Pearson correlation test shows linear correlations and it does not reveal the cause and effect relationships. Therefore, the role of vitamin $D$ in maintenance of insulin sensitivity or pathogenesis of insulin resistance is not rejected through this study.

\section{Methods}

\section{Experimental Participants}

This cross-sectional study was conducted at Hospital Serdang and Universiti Putra in Malaysia to investigate the gene expression pattern of $P I 3 K / A K T$ pathway based on insulin resistance and vitamin D status.

The appropriate sample size has been calculated based on independent-samples t-test to compare the means between two groups by using statistical software package Gpower 3.17. The effect size has been used as $d=0.5$, the a error probability considered as 0.05 , and Power of $1-\beta$ error probability considered as 0.95 based on recommended values. The number of recruited individuals for the study was 100 in age group of 35-60 (50 Type II diabetic participants and 50 non-diabetics served as control group). Mean age was not significantly different between non-diabetic and diabetic participants and the number of men and women were equal in each group. Participants who had cancers, nephropathy complications, thyroid 
or parathyroid diseases and smokers were excluded from this study. The necessary approval was obtained from UPM ethic committee and coordination with the Health Ministry of Malaysia was fulfilled based on the applicable Malaysian laws (National Medical Research Register, (NMRR)). The study was conducted in accordance to the Declaration of Helsinki in its currently applicable version, the guidelines of the International Conference on Harmonization of Good Clinical Practice (ICH-GCP). Consent has been obtained from each participant after full explanation of the purpose and nature of all the procedures.

\section{Blood Collection In The Paxgene Blood Rna Tube}

For RNA isolation, $2.5 \mathrm{ml}$ blood was collected from fasted volunteers in PAXgene Blood RNA Tubes (Qiagen; cat. no. 762165, Germany). The system requires combined use of PAXgene Blood RNA Tubes for blood collection and RNA stabilization, followed by PAXgene Blood RNA Kit (Qiagen; cat. no. 762174, Germany). PAXgene Blood RNA tubes containing blood samples were kept at room temperature for around 8 hours and then transferred to the refrigerator to extract RNA a day after blood collection. During the pilot study, it was concluded that the integrity and purity of RNA was improved by storage of tubes at room temperature for about $8 \mathrm{hr}$ and deferred extraction for $24 \mathrm{hr}$ after blood collection compared to the extracted RNA $2 \mathrm{hr}$ after blood collection. This is also based on the Kit protocol recommendation that postpone of extraction for at least $2 \mathrm{hr}$ after blood collection is compulsory to get satisfactory result.

\section{Rna Extraction}

Extraction of RNA was started with a centrifugation step to pellet nucleic acids. The pellet was washed, suspended and incubated in optimized buffers with proteinase $\mathrm{K}(\mathrm{PK})$ to bring about protein digestion. An additional centrifugation through the PAXgene Shredder spin column was carried out to homogenize the cell lysate and remove residual cell debris, before the supernatant of the flow-through fraction was transferred to a fresh Microcentrifuge tube. Binding conditions were adjusted with ethanol and the lysate was applied to a PAXgene RNA spin column for a brief centrifugation. RNA selectively bounds to the PAXgene silica membrane as contaminants pass through during the centrifugation. Remaining contaminants were removed in several efficient wash steps. Between the first and second wash steps, the membrane was treated with DNase I (RNFD) to remove trace amounts of bounded DNA. After the wash steps, RNA was eluted in elution buffer and heat-denatured. Isolated RNA was measured at A260/A280 for purity control. The integrity and size distribution of RNA were checked by agarose gel electrophoresis and Ethidium Bromide staining. The respective ribosomal bands appeared sharp on the stained gel and $28 \mathrm{~S}$ ribosomal RNA bands presented with an intensity approximately twice that of the 18S RNA band.

\section{cDNA Synthesis}

Purified RNA sample was briefly incubated in gDNA Wipeout Buffer at $42^{\circ} \mathrm{C}$ for 2 minutes to effectively remove any contaminating genomic DNA and then it was used in reverse transcription to produce cDNA. 
QuantiTect Rev.Transcription Kit (Qiagen; cat. no. 205313, Germany) was used and reverse-transcription master mix was prepared on ice according to the manufacturer protocol. Template RNA (14 $\mu$ l) was thawed on ice and added to each tube containing reverse-transcription master mix. The tubes were incubated for $15 \mathrm{~min}$ at $42^{\circ} \mathrm{C}$ and then incubated for $3 \mathrm{~min}$ at $95^{\circ} \mathrm{C}$ to inactivate Quantiscript Reverse Transcriptase. Reverse-transcription reactions were stored on ice and transferred to the fridge at $-80^{\circ} \mathrm{C}$ until using in RT-PCR.

\section{Real-time Rt-pcr}

Optimization and quantitation of all the markers of interest (GAPDH, ACTIN, PTEN, AKT2, GLUT4, PDK1, PI3K and IRS1) were carried out on real time-PCR (Qiagen; cat. no. 204054, Germany). In this study, all the primers were designed by Qigen Company and stored in TE buffer in small aliquots at $-20^{\circ} \mathrm{C}$. A reaction mix include 2x QuantiFast SYBR Green PCR Master Mix, primers and RNase-free water was prepared according to the manufacturer instruction on ice and appropriate volumes dispensed into PCR vessels while programming the real-time cycler. Template cDNA was thawed on ice and added to the PCR vessels containing reaction mix ( $\leq 100 \mathrm{ng}$ /reaction). For two-step RT-PCR, the volume of the cDNA added (from the undiluted RT reaction) should not exceed $10 \%$ of the final PCR volume $(2 \mu \mathrm{l}$ of the cDNA was added in this study, as the final PCR volume was $20 \mu \mathrm{l})$. The cycling conditions were as follows: $95^{\circ} \mathrm{C}$ for $5 \mathrm{~min}$ (PCR initial activation step); $95^{\circ} \mathrm{C}$ for $10 \mathrm{~s}$ (denaturation); $60^{\circ} \mathrm{C}$ for $30 \mathrm{~s}$ (combined annealing/extension); followed by 40 cycles and it was performed on a Bio-Rad Real-Time PCR detection system (Bio-Rad; CFX96, USA).

An NTC containing all the components of the reaction except for the template was performed to enable detection of contamination. An RT-control including all the components of the reaction except for Quantiscript Reverse Transcriptase was performed to detect probable genomic DNA contamination.

\section{Data Presentation And Calculations Through Relative Quantification}

Target nucleic acids can be quantified using either absolute quantification or relative quantification. With relative quantification, the amounts of the target genes and the reference gene within the same sample were determined and ratios were calculated between each target gene and the reference gene. Then these normalized values were used to compare the differential gene expression in different samples. In this method, the amount of internal reference gene relative to a calibrator (fold change between two $\mathrm{Ct}$ values) is given by the equation [15]: Fold difference $=2^{-\Delta \mathrm{Ct}}$.

\section{Serum Vitamin D (cholecalciferol) Analysis}


In order to measure serum vitamin D3 concentration of participants, HPLC method [16] was employed. Agilent 1100 machine, quaternary pump and Kinetex 5u C18 100A $250 \times 4.6$ mm column (Phenomenex, USA) was used in reverse-phase condition. Mobile phase was in an isocratic gradient; acetonitrile and methanol with the ratio of solvent 88:12, filtered and degassed to avoid any air bubbles and contamination. The flow rate was set at $1 \mathrm{~mL} / \mathrm{min}$ and $20 \mathrm{uL}$ per injection sample at 40囚 C. The HPLC unit was an integrated system with a UV-detector at $265 \mathrm{~nm}$ and data analysis was run by using ChemStation Operation System. $500 \mathrm{uL}$ of plasma was added to $350 \mathrm{uL}$ of methanol and 2-propanol (80:20 by volume). The tubes were mixed in a vortex mixer for $30 \mathrm{~s}$. Vitamin D3 was extracted by shaking three times ( $60 \mathrm{~s}$ each time) with $2 \mathrm{~mL}$ of hexane. The phases were separated by centrifugation and the upper organic phase was transferred to a conical tube and dried under nitrogen gas. The residue was dissolved in $100 \mathrm{uL}$ of water and methanol (with the ratio of 76:4). The sample was filtered by using nonsterile polyvinyl difluoride (PVDF) filter with the pore size of $0.22 \mu \mathrm{m}$ and diameter of $13 \mathrm{~mm}$ (AMTEC brand, Malaysia) and eluent was collected in $1.5 \mathrm{~mL}$ amber vial. Calibration curves were constructed using six different concentrations of vitamin D3 $(3.125,6.25,12.5,25,50$ and $100 \mathrm{ng} / \mathrm{mL})$ as a reference standard. Concentration of vitamin $D$ of each participants were stratified into three groups according to their serum vitamin D levels as: Optimal $(20-80 \mathrm{ng} / \mathrm{mL})$, Deficiency $(<20 \mathrm{ng} / \mathrm{mL})$ and Toxicity $(>$ $80 \mathrm{ng} / \mathrm{mL}$ ). Coefficient variation in this study was less than $10 \%$. The correlation coefficient in Standard Curve was $r 2=0.98$ while the equation gradient was $y=0.112 x$.

\section{Statistical Analysis}

Each experiment was performed three times and all data were expressed as means \pm SE. Statistical analysis was performed by using SPSS 21.0 statistical software package (SPSS Inc., Chicago, IL, USA). Shapiro-Wilk test was performed to normalize the data. Independent-samples t-test was applied to compare the means between two groups and threshold of significance was defined as a $\mathrm{P}<0.05$. Pearson correlation test was used as appropriate to analyze the relationships between serum vitamin $D$ concentration and expression level of genes. One-way ANOVA was used to compare differences between the groups based on duration of diabetes in diabetic participants. Levene's test was used to check significant differences $(P<0.05)$ revealed by ANOVA.

\section{Abbreviations}

AKT (Protein Kinase B); GLUT4 (Glucose Transporter 4); GS (Glycogen Synthase); IR (Insulin receptor); IRS (Insulin-receptor substrate); PDK (Phosphoinositide-Dependent Kinase); PI3K (Phosphatidylinositol 3kinase); PIP2 (Phosphotidylinositol-4,5-bisphosphate); PIP3 (Phosphotidylinositol-3,4,5-triphosphate); PKC (Protein Kinase C); PTPs (Protein Tyrosine Phosphatases); PTEN (Phosphatase and TENsin homolog deleted on chromosome 10)

\section{Declarations}

Ethics approval and consent to participate 
The necessary approval was obtained from UPM ethic committee. The study was conducted in accordance to the Declaration of Helsinki in its currently applicable version, the guidelines of the International Conference on Harmonization of Good Clinical Practice (ICH-GCP) and coordination with the Health Ministry of Malaysia was fulfilled based on the applicable Malaysian laws (National Medical Research Register, (NMRR)). Written consent has been obtained from each participant after full explanation of the purpose and nature of all procedures used. Ref. no: UPM/TNCPI/RMC/JKEUPM /1.4.18.1/F1

\section{Consent for publication}

Not applicable

\section{Availability of data and materials}

The data that support the findings of this study are available.

\section{Competing interests}

The authors declare that they have no competing interests.

\section{Funding}

This work was financially supported by the Ministry of Higher Education of Malaysia (Fundamental Research Grant Scheme (grant number: 14-554-20427)).

The funding bodies played no role in design of the study, sample collection, analysis, interpretation of data and writing of manuscript.

\section{Authors' contributions}

SAHK $^{1}$, MSAM $^{1}$ and $\mathbf{H K}^{6}$ were responsible for the study concept and design. SAHK ${ }^{1}$ and $\mathrm{JAA}^{3}$ contributed to data acquisition. $\mathbf{M F S}^{2}$ assisted $\mathbf{S A H K}{ }^{1}$ with data analysis and interpretation of findings. $\mathbf{S A H K}^{1}$ drafted the manuscript. MSAM ${ }^{1}, \mathbf{H K}^{6}, \mathbf{Z R}^{4}$ and $\mathbf{R M A}^{5}$ provided critical revision of the manuscript for important intellectual content and approved final version for publication. All authors read and approved the final manuscript.

\section{Acknowledgement}

Not applicable

\section{References}

1. Wasserman DH, Ayala JE, "Interaction of physiological mechanisms in control of muscle glucose uptake.," Clin. Exp. Pharmacol. Physiol., vol. 32, no. 4, pp. 319-23, Apr. 2005. 
2. Nystrom FH, Quon MJ, "Insulin signalling: metabolic pathways and mechanisms for specificity.", Cell. Signal., vol. 11, no. 8, pp. 563-74, Aug. 1999.

3. Shi K, et al., "Protein-tyrosine phosphatase 1B associates with insulin receptor and negatively regulates insulin signaling without receptor internalization.," J. Biochem., vol. 136, no. 1, pp. 89-96, Jul. 2004.

4. Saltiel AR, Kahn CR, "Insulin signalling and the regulation of glucose and lipid metabolism.," Nature, vol. 414, no. 6865, pp. 799-806, Dec. 2001.

5. Bryant NJ, Govers R, James DE, "Regulated transport of the glucose transporter GLUT4," Nat. Rev. Mol. Cell Biol., vol. 3, no. 4, pp. 267-277, Apr. 2002.

6. Fragoso R, Barata JT, "PTEN and leukemia stem cells.," Adv. Biol. Regul., vol. 56, pp. 22-9, Sep. 2014.

7. Alsadat S, Khorami H, Movahedi A, Kuzwah K, Mutalib A, Sokhini M. PI3K / AKT pathway in modulating glucose homeostasis and its alteration in Diabetes. Ann Med Biomed Sci. 2015;1(2):4655 .

8. Leslie NR, Dixon MJ, Schenning M, Gray A, Batty IH. Distinct inactivation of PI3K signalling by PTEN and 5-phosphatases. Adv Biol Regul. Jan. 2012;52(1):205-13.

9. Johnston AM, Pirola L, Van Obberghen E. Molecular mechanisms of insulin receptor substrate protein-mediated modulation of insulin signalling. " FEBS Lett. Jul. 2003;546(1):32-6.

10. Ravichandran LV, Chen H, Li Y, Quon MJ, "Phosphorylation of PTP1B at Ser(50) by Akt impairs its ability to dephosphorylate the insulin receptor.," Mol. Endocrinol., vol. 15, no. 10, pp. 1768-80, Oct. 2001.

11. Choi DP, et al., "Serum 25-Hydroxyvitamin D and Insulin Resistance in Apparently Healthy Adolescents," PLoS One, vol. 9, no. 7, p. e103108, Jul. 2014.

12. Borges CC, Salles AF, Bringhenti I, Souza-Mello V, Mandarim-de-Lacerda CA, Aguila MB. Adverse effects of vitamin $D$ deficiency on the Pi3k/Akt pathway and pancreatic islet morphology in dietinduced obese mice. Mol Nutr Food Res. Feb. 2016;60(2):346-57.

13. Yang $\mathrm{J}$, et al. The role of 1,25-dyhydroxyvitamin D3 in mouse liver ischemia reperfusion injury: regulation of autophagy through activation of MEK/ERK signaling and PTEN/PI3K/Akt/mTORC1 signaling. " Am J TransI Res. 2015;7(12):2630-45.

14. Zaulkffali AS, et al., "Vitamins D and E Stimulate the PI3K-AKT Signalling Pathway in InsulinResistant SK-N-SH Neuronal Cells," Nutrients, vol. 11, no. 10, p. 2525, Oct. 2019.

15. Livak KJ, Schmittgen TD, "Analysis of Relative Gene Expression Data Using Real-Time Quantitative PCR and the $2-\Delta \Delta$ CT Method," Methods, vol. 25, no. 4, pp. 402-408, Dec. 2001.

16. Turpeinen U, Hohenthal U, Stenman U-H. "Determination of 25-Hydroxyvitamin D in Serum by HPLC and Immunoassay," Clin. Chem., vol. 49, no. 9, 2003.

17. Schwartz SS, Epstein S, Corkey BE, Grant SFA, Gavin JR, Aguilar RB. The Time Is Right for a New Classification System for Diabetes: Rationale and Implications of the $\beta$-Cell-Centric Classification Schema. Diabetes Care. Feb. 2016;39(2):179-86. 
18. Wong JT, et al., "Pten (phosphatase and tensin homologue gene) haploinsufficiency promotes insulin hypersensitivity.," Diabetologia, vol. 50, no. 2, pp. 395-403, Feb. 2007.

19. Zhou J, et al. Inhibition of PTEN Activity Aggravates Post Renal Fibrosis in Mice with Ischemia Reperfusion-Induced Acute Kidney Injury. " Cell Physiol Biochem. 2017;43(5):1841-54.

20. Yang J, Chen Q. The Effects of Acetylation of PTEN on Hepatic Gluconeogenesis. J Alzheimer's Dis Park. Jun. 2016;6(3):1-7.

21. Zhou J, et al., "Inhibition of PTEN activity aggravates cisplatin-induced acute kidney injury," Oncotarget, vol. 8, no. 61, pp. 103154-103166, Nov. 2017.

22. Choi CS, Kim Y-B, Lee FN, Zabolotny JM, Kahn BB, Youn JH. "Lactate induces insulin resistance in skeletal muscle by suppressing glycolysis and impairing insulin signaling.," Am. J. Physiol. Endocrinol. Metab., vol. 283, no. 2, pp. E233-40, Aug. 2002.

23. Frangioudakis G, Ye J-M, Cooney GJ, “Both saturated and n-6 polyunsaturated fat diets reduce phosphorylation of insulin receptor substrate- 1 and protein kinase $B$ in muscle during the initial stages of in vivo insulin stimulation.," Endocrinology, vol. 146, no. 12, pp. 5596-603, Dec. 2005.

24. Singh LP, Gennerette D, Simmons S, Crook ED. "Glucose-induced insulin resistance of phosphatidylinositol 3 '-OH kinase and AKT/PKB is mediated by the hexosamine biosynthesis pathway.," J. Diabetes Complications, vol. 15, no. 2, pp. 88-96, Jan.

25. O'Brien RM, Streeper RS, Ayala JE, Stadelmaier BT, Hornbuckle LA. Insulin-regulated gene expression. " Biochem Soc Trans. Aug. 2001;29:no. Pt 4, pp. 552-8.

26. Carlsson $P$, Mahlapuu M, “Forkhead transcription factors: key players in development and metabolism.," Dev. Biol., vol. 250, no. 1, pp. 1-23, Oct. 2002.

27. Pal A, et al., "PTEN Mutations as a Cause of Constitutive Insulin Sensitivity and Obesity," N. Engl. J. Med., vol. 367, no. 11, pp. 1002-1011, Sep. 2012.

28. Paintlia AS, Paintlia MK, Singh AK, Orak JK, Singh I, "Activation of PPAR- $y$ and PTEN cascade participates in lovastatin-mediated accelerated differentiation of oligodendrocyte progenitor cells," Glia, vol. 58, no. 14, pp. 1669-1685, Nov. 2010.

29. Gual P, Le Marchand-Brustel Y, Tanti J, "Positive and negative regulation of glucose uptake by hyperosmotic stress.," Diabetes Metab., vol. 29, no. 6, pp. 566-75, Dec. 2003.

30. Morino K, Petersen KF, Shulman GI, "Molecular mechanisms of insulin resistance in humans and their potential links with mitochondrial dysfunction.," Diabetes, vol. 55 Suppl 2, pp. S9-S15, Dec. 2006.

31. Colomiere M, Permezel M, Riley C, Desoye G, Lappas M, "Defective insulin signaling in placenta from pregnancies complicated by gestational diabetes mellitus.," Eur. J. Endocrinol., vol. 160, no. 4, pp. 567-78, Apr. 2009.

32. Ishibashi KI, Imamura T, Sharma PM, Huang J, Ugi S, Olefsky JM. Chronic endothelin-1 treatment leads to heterologous desensitization of insulin signaling in 3T3-L1 adipocytes. J Clin Invest. May 2001;107(9):1193-202. 
33. Liu YF, et al., "Insulin stimulates PKCzeta -mediated phosphorylation of insulin receptor substrate-1 (IRS-1). A self-attenuated mechanism to negatively regulate the function of IRS proteins.," J. Biol. Chem., vol. 276, no. 17, pp. 14459-65, Apr. 2001.

34. Zick Y. "Molecular basis of insulin action.," Novartis Found. Symp., vol. 262, pp. 36-50; disucssion 50 - 5, 265-8, Jan. 2004.

35. Zick Y, "Ser/Thr phosphorylation of IRS proteins: a molecular basis for insulin resistance.," SCi. STKE, vol. 2005 , no. 268 , p. pe4, Jan. 2005.

36. Wellen KE, Hotamisligil GS. "Inflammation, stress, and diabetes.," J. Clin. Invest., vol. 115, no. 5, pp. 1111-9, May 2005.

37. Simpson L, et al., "PTEN expression causes feedback upregulation of insulin receptor substrate 2.," Mol. Cell. Biol., vol. 21, no. 12, pp. 3947-58, Jun. 2001.

38. Farese RV, Sajan MP, Standaert ML, "Insulin-sensitive protein kinases (atypical protein kinase $\mathrm{C}$ and protein kinase B/Akt): actions and defects in obesity and type II diabetes.," Exp. Biol. Med. (Maywood)., vol. 230, no. 9, pp. 593-605, Oct. 2005.

39. Santoleri D, Titchenell PM, "Resolving the Paradox of Hepatic Insulin Resistance," Cell. Mol. Gastroenterol. Hepatol., vol. 7, no. 2, pp. 447-456, Jan. 2019.

40. Ducluzeau $\mathrm{PH}$, et al. Regulation by insulin of gene expression in human skeletal muscle and adipose tissue. Evidence for specific defects in type 2 diabetes. " Diabetes. May 2001;50(5):1134-42.

41. Nakashima N, Sharma PM, Imamura T, Bookstein R, Olefsky JM, "The tumor suppressor PTEN negatively regulates insulin signaling in 3T3-L1 adipocytes.," J. Biol. Chem., vol. 275, no. 17, pp. 12889-95, Apr. 2000.

42. Ono H, et al., "Regulation of phosphoinositide metabolism, Akt phosphorylation, and glucose transport by PTEN (phosphatase and tensin homolog deleted on chromosome 10) in 3T3-L1 adipocytes.," Mol. Endocrinol., vol. 15, no. 8, pp. 1411-22, Aug. 2001.

43. Butler M, et al., "Specific inhibition of PTEN expression reverses hyperglycemia in diabetic mice.," Diabetes, vol. 51, no. 4, pp. 1028-34, Apr. 2002.

44. Tong Z, et al., "Pancreas-specific Pten deficiency causes partial resistance to diabetes and elevated hepatic AKT signaling.," Cell Res., vol. 19, no. 6, pp. 710-9, Jun. 2009.

45. Wijesekara $\mathrm{N}$, et al., "Muscle-specific Pten deletion protects against insulin resistance and diabetes.," Mol. Cell. Biol., vol. 25, no. 3, pp. 1135-45, Feb. 2005.

46. Delibegovic M, et al., "Improved glucose homeostasis in mice with muscle-specific deletion of protein-tyrosine phosphatase 1B.," Mol. Cell. Biol., vol. 27, no. 21, pp. 7727-34, Nov. 2007.

47. Wang B, et al., "Differences in myocardial PTEN expression and Akt signalling in type 2 diabetic and nondiabetic patients undergoing coronary bypass surgery," Clin. Endocrinol. (Oxf)., vol. 74, no. 6, pp. 705-713, Jun. 2011.

48. Ye Y, et al., "Phosphodiesterase-3 inhibition augments the myocardial infarct size-limiting effects of exenatide in mice with type 2 diabetes," Am. J. Physiol. Circ. Physiol., vol. 304, no. 1, pp. H131-H141, 
Jan. 2013.

49. Qian J, Ling S, Castillo AC, Long B, Birnbaum Y, Ye Y. Regulation of phosphatase and tensin homolog on chromosome 10 in response to hypoxia. Am J Physiol Circ Physiol. May 2012;302(9):H1 806-17.

50. Hu Z, et al., "PTEN Inhibition Improves Muscle Regeneration in Mice Fed a High-Fat Diet," Diabetes, vol. 59, no. 6, pp. 1312-1320, Jun. 2010.

51. Ryu D, et al., "Endoplasmic Reticulum Stress Promotes LIPIN2-Dependent Hepatic Insulin Resistance," Diabetes, vol. 60, no. 4, pp. 1072-1081, Apr. 2011.

52. Neto-Ferreira R, Rocha VN, Souza-Mello V, Mandarim-de-Lacerda CA, de Carvalho JJ. Pleiotropic effects of rosuvastatin on the glucose metabolism and the subcutaneous and visceral adipose tissue behavior in C57BI/6 mice. Diabetol Metab Syndr. Jul. 2013;5(1):32.

53. Sasaki T, Sasaki J, Sakai T, Takasuga S, Suzuki A, "The physiology of phosphoinositides.," Biol. Pharm. Bull., vol. 30, no. 9, pp. 1599-604, Sep. 2007.

54. Park WS, et al. Comprehensive identification of PIP3-regulated PH domains from C. elegans to $\mathrm{H}$. sapiens by model prediction and live imaging. " Mol Cell. May 2008;30(3):381-92.

55. Várnai P, et al., "Selective cellular effects of overexpressed pleckstrin-homology domains that recognize Ptdlns(3,4,5)P3 suggest their interaction with protein binding partners.," J. Cell Sci., vol. 118, no. Pt 20, pp. 4879-88, Oct. 2005.

56. Manna P, Jain SK, "Hydrogen sulfide and L-cysteine increase phosphatidylinositol 3,4,5-trisphosphate (PIP3) and glucose utilization by inhibiting phosphatase and tensin homolog (PTEN) protein and activating phosphoinositide 3-kinase (PI3K)/serine/threonine protein kinase (A," J. Biol. Chem., vol. 286, no. 46, pp. 39848-59, Nov. 2011.

57. Rains JL, Jain SK, "Oxidative stress, insulin signaling, and diabetes.," Free Radic. Biol. Med., vol. 50, no. 5, pp. 567-75, Mar. 2011.

58. Chen C-Y, Chen J, He L, Stiles BL, "PTEN: Tumor Suppressor and Metabolic Regulator," Front. Endocrinol. (Lausanne)., vol. 9, p. 338, Jul. 2018.

59. McLoughlin NM, Mueller C, Grossmann TN. The Therapeutic Potential of PTEN Modulation: Targeting Strategies from Gene to Protein. " Cell Chem Biol. Jan. 2018;25(1):19-29.

60. Xue R, et al. Selective inhibition of PTEN preserves ischaemic post-conditioning cardioprotection in STZ-induced Type 1 diabetic rats: role of the PI3K/Akt and JAK2/STAT3 pathways. " Clin Sci (Lond). Mar. 2016;130(5):377-92.

61. Pal A, et al., "PTEN mutations as a cause of constitutive insulin sensitivity and obesity.," N. Engl. J. Med., vol. 367, no. 11, pp. 1002-11, Sep. 2012.

62. Wang $X$, et al., "Cross talk between miR-214 and PTEN attenuates glomerular hypertrophy under diabetic conditions," Sci. Rep., vol. 6, no. 1, p. 31506, Nov. 2016.

63. Sumita T, et al. Mediobasal hypothalamic PTEN modulates hepatic insulin resistance independently of food intake in rats. Am J Physiol Metab. Jul. 2014;307(1):E47-60. 
64. Wang B, et al., "Differences in myocardial PTEN expression and Akt signalling in type 2 diabetic and nondiabetic patients undergoing coronary bypass surgery.," Clin. Endocrinol. (Oxf)., vol. 74, no. 6, pp. 705-13, Jun. 2011.

65. Arkun Y. Dynamic Modeling and Analysis of the Cross-Talk between Insulin/AKT and MAPK/ERK Signaling Pathways. PLoS One. Mar. 2016;11(3):e0149684.

66. Somvanshi PR, Tomar M, Kareenhalli V. "Computational Analysis of Insulin-Glucagon Signalling Network: Implications of Bistability in Metabolic Homeostasis and Disease states," 2019.

67. Wang G, "Raison d'être of insulin resistance: the adjustable threshold hypothesis.," J. R. Soc. Interface, vol. 11, no. 101, p. 20140892, Dec. 2014.

68. Sulaimanov N, Klose M, Busch H, Boerries M. "Understanding the mTOR signaling pathway via mathematical modeling.", Wiley Interdiscip. Rev. Syst. Biol. Med., vol. 9, no. 4, 2017.

69. Wang G, "Global quantitative biology can illuminate ontological connections between diseases," Quant. Biol., vol. 5, no. 2, pp. 191-198, Jun. 2017.

70. Giri L, Mutalik VK, Venkatesh KV. A steady state analysis indicates that negative feedback regulation of PTP1B by Akt elicits bistability in insulin-stimulated GLUT4 translocation. Theor Biol Med Model. 2004;1:2.

71. Tan S-X, et al. Amplification and demultiplexing in insulin-regulated Akt protein kinase pathway in adipocytes. " J Biol Chem. Feb. 2012;287(9):6128-38.

72. Ferrell JE, "Self-perpetuating states in signal transduction: positive feedback, double-negative feedback and bistability.," Curr. Opin. Cell Biol., vol. 14, no. 2, pp. 140-8, Apr. 2002.

73. Angeli D, Ferrell JE, Sontag ED, "Detection of multistability, bifurcations, and hysteresis in a large class of biological positive-feedback systems.," Proc. Natl. Acad. Sci. U. S. A., vol. 101, no. 7, pp. 1822-7, Feb. 2004.

74. Ferrell JE, "Tripping the switch fantastic: how a protein kinase cascade can convert graded inputs into switch-like outputs.," Trends Biochem. Sci., vol. 21, no. 12, pp. 460-6, Dec. 1996.

75. Harel Z, Flanagan P, Forcier M, Harel D. Low Vitamin D Status Among Obese Adolescents: Prevalence and Response to Treatment. J Adolesc Heal. May 2011;48(5):448-52.

76. Peterson CA, Tosh AK, Belenchia AM, "Vitamin D insufficiency and insulin resistance in obese adolescents.," Ther. Adv. Endocrinol. Metab., vol. 5, no. 6, pp. 166-89, Dec. 2014.

77. Garanty-Bogacka B, et al. Serum 25-hydroxyvitamin D (25-OH-D) in obese adolescents. " Endokrynol Pol. 2011;62(6):506-11.

78. Ortlepp JR, Metrikat J, Albrecht M, von Korff A, Hanrath P, Hoffmann R, "The vitamin D receptor gene variant and physical activity predicts fasting glucose levels in healthy young men.," Diabet. Med., vol. 20, no. 6, pp. 451-4, Jun. 2003.

79. Boucher BJ, Mannan N, Noonan K, Hales CN, Evans SJ. Glucose intolerance and impairment of insulin secretion in relation to vitamin D deficiency in east London Asians. " Diabetologia. Oct. 1995;38(10):1239-45. 
80. lyengar S, Hamman RF, Marshall JA, Majumder PP, Ferrell RE. On the role of vitamin D binding globulin in glucose homeostasis: results from the San Luis Valley Diabetes Study. " Genet Epidemiol. 1989;6(6):691-8.

81. Calle C, et al. Genomic actions of 1,25-dihydroxyvitamin D3 on insulin receptor gene expression, insulin receptor number and insulin activity in the kidney, liver and adipose tissue of streptozotocininduced diabetic rats. BMC Mol Biol. 2008;9(1):65.

82. Peeyush KT, Savitha B, Sherin A, Anju TR, Jes P, Paulose CS, "Cholinergic, dopaminergic and insulin receptors gene expression in the cerebellum of streptozotocin-induced diabetic rats: functional regulation with Vitamin D3 supplementation.," Pharmacol. Biochem. Behav., vol. 95, no. 2, pp. 21622, Apr. 2010.

83. Blanco-Aparicio C, Renner O, Leal JFM, Carnero A, "PTEN, more than the AKT pathway," Carcinogenesis, vol. 28, no. 7, pp. 1379-1386, Jul. 2007.

84. Stiles B, Groszer M, Wang S, Jiao J, Wu H, “PTENless means more," Dev. Biol., vol. 273, no. 2, pp. 175-184, Sep. 2004.

85. Butler M, et al., "Specific Inhibition of PTEN Expression Reverses Hyperglycemia in Diabetic Mice," Diabetes, vol. 51, no. 4, pp. 1028-1034, Apr. 2002.

86. Kurlawalla-Martinez C, Stiles B, Wang Y, Devaskar SU, Kahn BB, Wu H, "Insulin Hypersensitivity and Resistance to Streptozotocin-Induced Diabetes in Mice Lacking PTEN in Adipose Tissue," Mol. Cell. Biol., vol. 25, no. 6, pp. 2498-2510, Mar. 2005.

87. Kamo N, Ke B, Busuttil RW, Kupiec-Weglinski JW. PTEN-mediated akt//-Catenin/foxo1 signaling regulates innate immune responses in mouse liver ischemia/reperfusion injury. Hepatology. Jan. 2013;57(1):289-98.

88. Peyrou M, et al., "Hepatic PTEN deficiency improves muscle insulin sensitivity and decreases adiposity in mice," J. Hepatol., vol. 62, no. 2, pp. 421-429, Feb. 2015.

89. Xu G, et al., "MiR-26b modulates insulin sensitivity in adipocytes by interrupting the PTEN/PI3K/AKT pathway," Int. J. Obes., vol. 39, no. 10, pp. 1523-1530, Oct. 2015.

90. Li G, et al., "miR-26b Promotes 3T3-L1 Adipocyte Differentiation Through Targeting PTEN," DNA Cell Biol., vol. 36, no. 8, pp. 672-681, Aug. 2017.

91. Malek M, et al., "PTEN Regulates PI(3,4)P2 Signaling Downstream of Class I PI3K," Mol. Cell, vol. 68, no. 3, pp. 566-580.e10, Nov. 2017.

92. Li A, Qiu M, Zhou H, Wang T, Guo W, “PTEN, Insulin Resistance and Cancer," Curr. Pharm. Des., vol. 23, no. 25, pp. 3667-3676, Sep. 2017.

93. Manna P, Jain SK, "Hydrogen sulfide and L-cysteine increase phosphatidylinositol 3,4,5-trisphosphate (PIP3) and glucose utilization by inhibiting phosphatase and tensin homolog (PTEN) protein and activating phosphoinositide 3-kinase (PI3K)/serine/threonine protein kinase (A," J. Biol. Chem., vol. 286, no. 46, pp. 39848-59, Nov. 2011.

\section{Figures}




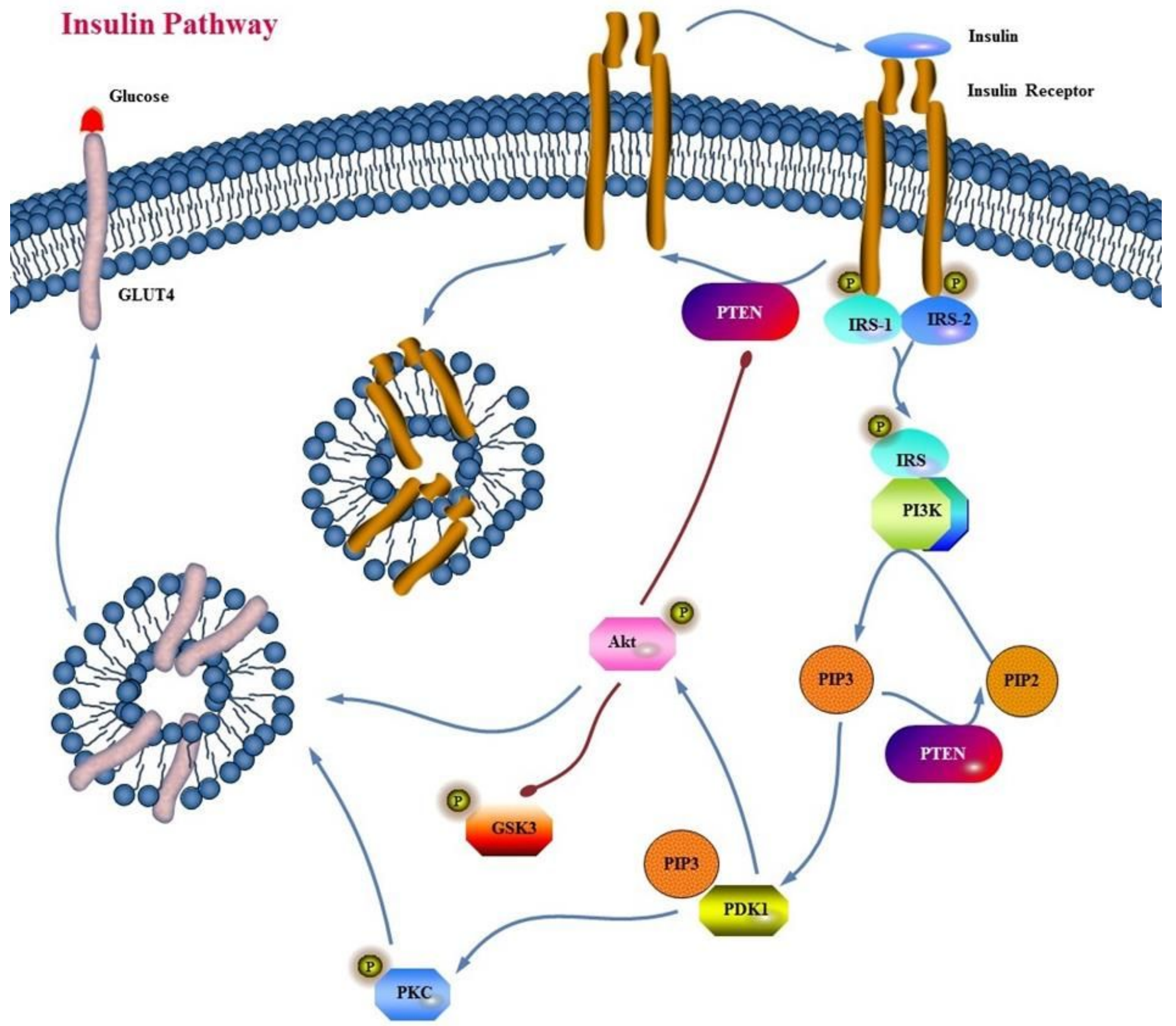

\section{Figure 1}

Insulin Signalling Pathway Insulin initiates its function by interacting with the insulin receptor which can be reversely dephosphorylated by PTEN phosphatase. Phosphorylated IRS1 binds and activates PI3K which causes conversion of PIP2 to PIP3 (PTEN dephosphorylates PIP3 back to PIP2). Allosteric interaction of PIP3 with PDK1 leads to AKT/PKB and PKC phosphorylation to activate GLUT4 translocation from intracellular vesicular compartment to plasma membrane. The insulin signalling pathway includes multiple feedback loops as phosphorylated/activated AKT phosphorylates and 
negatively regulates PTEN. This phosphorylation impairs the function of PTEN to dephosphorylate IR and IRS1. 